\title{
Producer Response to Public disclosure OF FOOD-SAFETY INFORMATION
}

\author{
Michael Ollinger, ANd John Bovay
}

\begin{abstract}
Beginning in 2003, the USDA's Food Safety and Inspection Service (FSIS) put forth a series of Federal Register announcements regarding the public disclosure of results of tests for Salmonella in chicken carcasses. In particular, FSIS suggested in 2003 that it might disclose the identities of any slaughter or ground meat plant failing its Salmonella tests if test performance did not improve, and in 2004 the service increased regulatory scrutiny of plants not meeting FSIS Salmonella standards. In 2006, FSIS introduced a more easily-understood measure of food-safety quality and indicated that public disclosure would be forthcoming if results of tests for Salmonella did not improve; FSIS targeted the chicken-slaughter industry with a high degree of specificity. In 2008, FSIS began reporting the names of chicken-slaughter plants with poor performance on tests for Salmonella in chicken carcasses. This article examines the effects of these regulatory actions on Salmonella test outcomes. We find that (1) announcements in 2003 and 2004 were associated with improved performance by the poorestperforming chicken-slaughter plants; (2) the introduction of an easily-understood measure of foodsafety quality and the threat of disclosure of the identities of poorly performing plants in 2006 were associated with improved performance by all chicken-slaughter plants; and (3) implementation of a public disclosure program in 2008 was associated with improvements among better-performing chicken-slaughter plants.
\end{abstract}

Key words: Chicken slaughter, Salmonella, food safety, disclosure, FSIS, regulation, moral hazard.

JEL codes: D22, D23, K23, L22, L51.

Salmonella in chicken is a major public health concern. Painter et al. (2013) estimated that in the United States, 650,000 people got sick annually from poultry contaminated with Salmonella and other pathogens from 1998 to 2008. Moreover, the Interagency Food Safety Analytics Collaboration (2018) reports that about $60 \%$ of the 1,255 foodborne illness outbreaks over 1998-2016 were due to Salmonella; about $19 \%$ of these were caused by poultry (Painter et al. 2013).

Michael Ollinger is an agricultural economist with the Economic
Research Service of the USDA. John Bovay was an assistant pro-
fessor in the Department of Agricultural and Resource Economics
at the University of Connecticut at the time of this research, and
will be an assistant professor in the Department of Agricultural
and Applied Economics at Virginia Tech effective August 2019.
Correspondence may be sent to: Michael.Ollinger@usda.gov

First published online by Oxford University Press on behalf of the Agricultural and Applied Economics Association.
The USDA's Food Safety and Inspection Service (FSIS) promulgated the Pathogen Reduction and Hazard Analysis and Critical Control Point (PR/HACCP) rule in 1996 to better control pathogens in meat and poultry. The regulation included a mix of required food-safety practices and a performance standard (tolerance) for Salmonella. These provisions had a substantial short-term impact, reducing annual illnesses from chicken-related salmonellosis in the United States by 190,000 from 1996 to 2000 (Williams and Ebel 2012). However, the effect was short-lasting. FSIS data show that the share of samples from chickens carcasses testing positive for Salmonella rose from 0.09 to 0.14 from 2000 to 2005. Meanwhile, the shares of samples testing positive for Salmonella dropped by $59 \%$ in ground beef and $50 \%$ in market hogs, $72 \%$ in steer and heifers, and about $50 \%$ in cow carcasses. The FSIS noticed these trends and starting in 2003 undertook a series of actions 
directed at the chicken industry that were followed by a drop in the share of samples testing positive for Salmonella from 0.14 to 0.05 over from 2005 to 2010.

This paper relies on the ideas on moral hazard developed by Holmström (1979, 1982), Grossman and Hart (1983), and others to explain the improvement in Salmonella test results. Incentives for moral hazard occur when buyers cannot observe a quality attribute such as food safety, and the provision of quality is costly (Holmström 1979; Grossman and Hart 1983). Additional information provides a better assessment of performance and can offset moral hazard (Holmström 1979).

In this paper, we use plant-level data to examine the performance of chickenslaughter plants on tests for Salmonella in chicken carcasses, in the context of Federal Register (FR) announcements by FSIS that culminated in the public disclosure of plant performance on Salmonella tests. We provide evidence that the FR announcements were strongly associated with improved performance on FSIS tests for Salmonella in chicken carcasses.

The paper most closely follows Jin and Leslie (2003), who found that restaurant health-inspection scores rose after Los Angeles County required restaurants to place hygiene-quality cards in their windows, and Bennear and Olmstead (2008), who found that health violations dropped in Massachusetts after the disclosure of violations of the 1996 Amendments to the Safe Drinking Water Act. This paper differs from these articles and other research in several important ways. First, unlike Jin and Leslie (2003), this paper examines public disclosure in a market comprised of commercial buyers and industrial suppliers rather than a market in which final consumers were well-apprised of the disclosed information and could switch vendors at relatively low cost. Second, it provides evidence that public disclosure of poor performance on Salmonella tests helped overcome moral hazard in FSIS testing practices and contributed to better performance on Salmonella tests. Third, this paper provides evidence that the credible threat of quality disclosure (subsequently implemented) may have induced greater improvement than the actual disclosure requirement. In our context, the credible threat was accompanied with improved precision in the categorization of sellers by performance category. Finally, the paper illustrates the differential responses of sellers with good and poor food-safety records to policy changes. ${ }^{1}$

In the following sections, we provide an overview of the approaches used to limit the effects of moral hazard in meat and poultry industries, and review recent policy changes regarding inspection of chicken for Salmonella. We then discuss our data and empirical strategy. Our results show that FSIS policy changes are associated with improvements in Salmonella test results, and that the anticipation of pending policy change and disclosure of information about poorly-performing plants both affected plant-level Salmonella outcomes. The article concludes with a discussion of the mechanisms that may explain the observed results.

\section{Food Safety Information and Moral Hazard}

Food safety is characterized by asymmetric information between sellers and buyers and can lead to Akerlof-type market breakdowns (Akerlof 1970; Dulleck, Kerschbamer, and Sutter 2011). However, second-best solutions often emerge to ensure that sellers provide products of sufficient quality (Holmström 1979; Grossman and Hart 1983). These second-best solutions can come from either the private or public sectors. Private-sector solutions may include contracts between buyers and sellers. Golan et al. (2004) and Ollinger and Bovay (2018) have shown that suppliers and buyers offering and searching for higher quality seek each other out, as suppliers undertake additional practices to better assure food safety in exchange for higher prices or sales guarantees. Ollinger, Moore, and Chandran (2004) report that at the time of their survey, about two-thirds of chicken plants had contracts with buyers that were more stringent than the food-safety standards of FSIS.

Public health authorities (FSIS) also monitor plant food safety practices and meat and poultry food safety. Starbird (2005) argues that standards (tolerances for pathogens in meat) can limit moral hazard by providing regulators and buyers with better information about food safety. Information from public

\footnotetext{
1 This research extends research by the authors in Ollinger et al. (2017), which provides some evidence that public disclosure of Salmonella test results improves performance on subsequent Salmonella tests.
} 
health authorities motivates other market solutions. Product recalls may lead to high liability costs (Dulleck, Kerschbamer, and Sutter 2011) and encourage firms to invest in food safety (Marino 1997). Product recalls also negatively affect producers' reputations for food safety and have been associated with adverse investor reactions (Pozo and Schroeder 2016), weak futures prices (Lusk and Schroeder 2002), and reductions in product demand (Piggott and Marsh 2004; Thomsen, Shiptsova, and Hamm 2006).

Care must be taken in the construction of food-safety standards. FSIS promulgated the Salmonella standard for chicken carcasses in 1996 under the PR/HACCP rule. As described in 2006 in the FR (71 FR 9772), FSIS sets its Salmonella standard such that plants operating at the baseline level have an $80 \%$ chance of meeting the standard. ${ }^{2}$ The baseline, and therefore the standard, can change only if there is a downward trend in Salmonella levels. This gives rise to moral hazard because plants preferring a weak standard and the associated lower compliance costs would have no incentive to perform better than the standard unless required by a customer. The weak incentive for food safety was reflected in performance on Salmonella tests, as the share of whole chicken samples testing positive for Salmonella rose from $7 \%$ to $14 \%$ from 2000 to 2005. Better performance on Salmonella tests was possible: $40 \%$ of all plants had half the number of permitted positive Salmonella test results, or better. Still, another $40 \%$ of all plants failed to even meet the standard.

If moral hazard reduces the incentive to control Salmonella, then better information should encourage better Salmonella control because plants with poor food safety could lose sales to competitors offering the same product with lower Salmonella levels. Below, we examine the impact of disclosure of past results tests for Salmonella in chicken on plant performance on subsequent tests for Salmonella.

\footnotetext{
2 See https://www.gpo.gov/fdsys/pkg/FR-2006-02-27/pdf/061783.pdf. The FSIS document entitled "Changing the Set Sizes in Raw Ground Poultry Sampling" (https://www.fsis.usda.gov/wps/ wcm/connect/fd2683bb-c409-4986-9d8a-49bb88ff6d80/Set_Sizes_ in_Ground_Poultry_Sampling.pdf?MOD=AJPERES) indicates that FSIS wanted each Salmonella sample set to have a sufficient number of samples over an extended period of time to adequately evaluate a plant's process controls. FSIS assumed two months and 50 samples would be necessary. The precise number of samples was based on a policy of setting a level at which an establishment would have an $80 \%$ probability of passing.
}

\section{Background on FSIS Regulations}

When it issued the PR/HACCP rule in 1996, the FSIS mandated that meat and poultry plants have a HACCP process control plan and required most slaughter and ground meat and poultry plants to meet standards for Salmonella. FSIS inspectors monitored compliance with HACCP process control tasks and also Sanitation Standard Operating Procedures (SSOPs) and issued noncompliance reports if tasks were poorly performed (Ollinger and Bovay 2018). ${ }^{3}$ The introduction of Salmonella testing marked a distinct departure from past regulatory oversight. Under this scheme, inspectors oversaw Salmonella testing and set standards, allowing chicken slaughter to have no more than 12 out of a set of 51 samples test positive for Salmonella; in 2011, FSIS reduced the tolerance to no more than 5 out of 51 samples. The FSIS sampled worseperforming and larger plants more frequently. Enforcement powers were weak: plants that failed testing three consecutive times faced more severe regulatory actions but were permitted to continue production. There were no stricter enforcement options. In 2001, the Fifth Circuit Court ruled that FSIS could not use poor Salmonella test results to justify the withdrawal of a plant's Grant of Inspection, which would have shut the plant down (Ollinger and Mueller 2003).

The FSIS began a dialogue on food safety in 2003 when it proposed in an FR announcement to publicly disclose the plant-level test results for Salmonella of all meat and poultry slaughter and ground meat plants. ${ }^{4}$ The FSIS eventually withdrew the proposal but did make test results available to producers upon request and published aggregate results. In 2004, the FSIS reported improved performance on Salmonella tests in meat industries but worse performance in chicken and indicated that it would increase regulatory oversight of poorly-performing plants (Becker 2004).

In 2006, the FSIS announced that it would obtain access to sub-type pulsed-field gel electrophoresis (PFGE) to identify Salmonella

\footnotetext{
${ }^{3}$ SSOPs include pre-operational SSOPs, which are cleaning and sanitation tasks performed at the beginning or end of the production day, and operational SSOPs, which are cleaning tasks performed during production. HACCP process control tasks are tasks performed under each plant's HACCP plan. HACCP plans outline tasks necessary for the plant to maintain food safety.

4 See supplementary online appendix table A.1 for a summary of FSIS announcements and policy changes.
} 
and would share information with the Centers for Disease and Prevention (CDC) and other federal agencies. ${ }^{5}$ The FSIS also replaced its previous pass/fail system of rating plant performance on Salmonella tests with a system that had three categories of plant performance (see online supplementary table A.2). Plants with test results equal to no more than half the Salmonella standard were assigned to Category 1; plants with results exceeding the standard were given a Category 3 rating; Category 2 plants were neither Category 1 nor Category 3 . The FSIS also said that it would reduce regulatory stringency for Category 1 plants and increase stringency for Category 2 and 3 plants. ${ }^{6}$ Finally, the FSIS singled out Salmonella in chicken as a source of foodborne illness, indicated that only chicken-slaughter plant performance on Salmonella tests had worsened over 2000-2005, and warned that it would favor public disclosure of Salmonella test results if fewer than $90 \%$ of plants had Salmonella test results in Category 1.

The third FSIS action came on January 28, 2008 when, citing text from its 2006 FR announcement, the FSIS indicated that it would publish the names of chicken-slaughter plants performing at the Category 2 and 3 levels, effective March 28, 2008. By this time, chicken-slaughter plants had been under notice for nearly two years that public disclosure was coming for Category 2 and 3 plants if performance did not improve.

\section{Data}

We use administrative data from the FSIS on Salmonella test results over 2000-2010 for all chicken-slaughter plants that were in operation before 2004. The study's timeframe extends from the time PR/HACCP was fully implemented until FSIS ceased publicly disclosing the identities of Category 2 plants. Salmonella test results are not available for each

\footnotetext{
5 PFGE is a technique for separation of DNA molecules that emerged in the 1990 s as a way to facilitate public health authorities' efforts to match harmful pathogens found in contaminated foods to foods produced in factories. The widespread use of PFGE increased the likelihood of identifying a plant that was producing contaminated foods, subjecting them to potential liability.

${ }^{6}$ Regulatory stringency refers to the degree of oversight provided by FSIS: Category 2 plants were tested more frequently than Category 1 plants; Category 3 plants were tested more than Category 2 plants and received greater oversight, including strict enforcement of sanitation standards and the use of Food Safety Assessments to evaluate plant food safety operations.
}

plant-year because FSIS conducts Salmonella testing based on volume of production and past performance on Salmonella tests. As a result, some plants may have had multiple test cycles per year, while others may not have been tested at all. The FSIS data set includes the number of animals slaughtered, plant characteristics, and plant process controls (performance of HACCP tasks and SSOPs). Table 1 provides summary statistics and definitions of variables.

At the time of this study, testing of chicken carcasses was done in sample sets of 51 spanning a period of several weeks. Thus, testing could begin in one year and extend into the next year, leaving a partial sample set for analysis. We dropped 86 plant-year observations with 30 or fewer Salmonella samples to ensure that small, partial samples did not distort our results. ${ }^{7}$ Our final data set includes the results of tests for Salmonella in chicken carcasses for 1,361 plant-year observations of 185 young-chicken slaughter plants. The maximum number of samples for any plant was 158, giving a range of samples taken for any plant of 30 to 158 . About $99 \%$ of the plantyear observations in our final data set had between 30 and 110 test samples.

Figure 1 shows that for the mean plant, the yearly share of samples testing positive for $\mathrm{Sal}$ monella remained at about 0.12 over the 2001-2006 period, and then dropped dramatically to 0.07 to 0.05 over the $2007-10$ period. Summary statistics for hog-slaughter and ground beef (see online supplementary table A.3) show that the level of Salmonella in the chicken-slaughter industry was substantially higher than in other industries.

\section{Empirical Strategy}

Holmström (1979) asserts that better information can reduce moral hazard behavior. We have provided evidence showing that Salmonella levels dropped substantially as FSIS took several actions, including the disclosure of the identities of plants performing poorly on Salmonella tests. Our goal is to disentangle the

\footnotetext{
${ }^{7}$ If we had retained smaller partial sample sets, this might have biased our results. FSIS (2012) used data from Salmonella testing programs for ground chicken and ground turkey to confirm that there was no significant change in test results with respect to thresholds for sets with 30 observations, compared with 50 observations.
} 
Table 1. Summary Statistics

\begin{tabular}{lccc}
\hline & Mean & Range & S.D. \\
\hline 6 or fewer positive samples (Cat 1) & 0.699 & $0-1$ & 0.459 \\
4 or fewer positive samples & 0.548 & $0-1$ & 0.498 \\
2 or fewer positive samples & 0.357 & $0-1$ & 0.479 \\
1 or fewer positive samples & 0.243 & $0-1$ & 0.429 \\
Share Positive Samples & 0.099 & $0.0-0.627$ & 0.095 \\
Cat 2 in previous period & 0.303 & $0-1$ & 0.460 \\
Cat 3 in previous period & 0.081 & $0-1$ & 0.273 \\
Deflated Farm-to-Wholesale Price Spread & 0.224 & $0.167-0.279$ & 0.036 \\
Media Reports & 698.3 & $344.0-1665$ & 406.5 \\
Lag number of Salmonella recalls & 1.78 & $0.0-4.0$ & 1.36 \\
Number of Chickens Slaughtered (millions) & 48.03 & $0.048-124.2$ & 23.92 \\
Multi-species & 0.086 & $0-1$ & 0.280 \\
Age & 24.28 & $1-52$ & 13.3 \\
Multi-plant & 0.608 & $0-1$ & 0.488 \\
Process & 0.096 & $0-1$ & 0.295 \\
Share of pre-operation SSOPs not compliant with standards & 0.103 & $0.0-0.533$ & 0.098 \\
Share of operation SSOPs out of compliance with standards & 0.092 & $0.0-0.70$ & 0.088 \\
Share of HACCP tasks outs of compliance with standards & 0.036 & $0.0-0.627$ & 0.069 \\
Number of observations & 1,361 & & \\
\hline
\end{tabular}

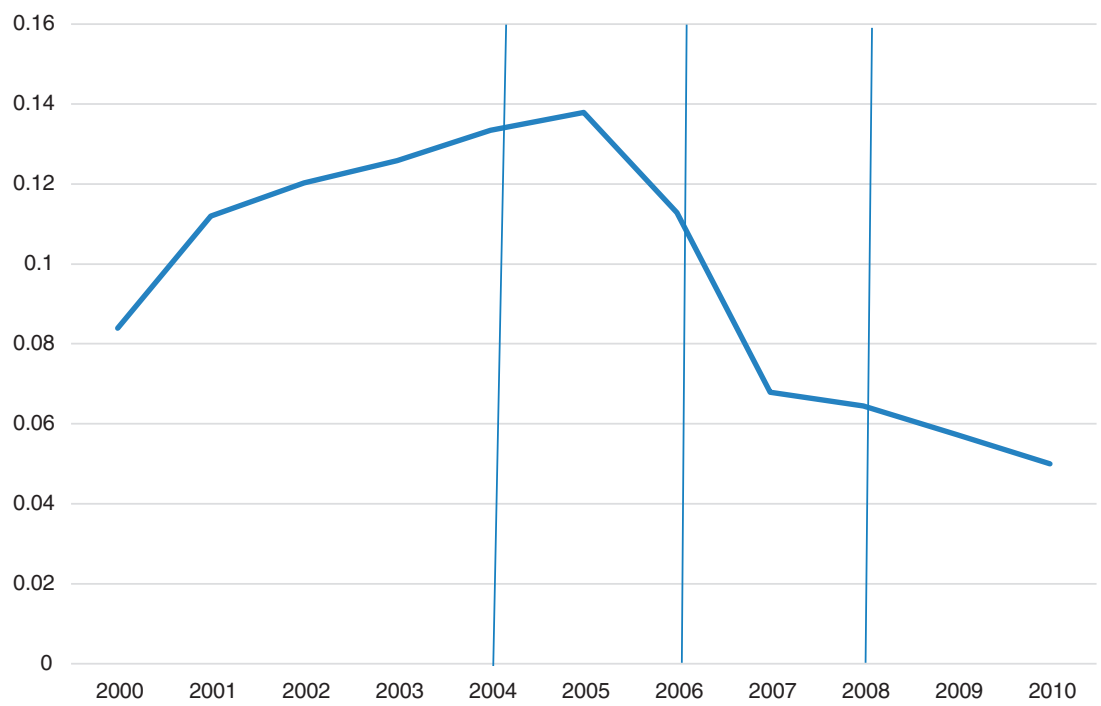

Figure 1. Mean plant-level Salmonella test results by year, 2000-2010.

Note: Share of chicken carcass samples testing positive for Salmonella, mean of plant-level annual averages. Vertical lines represent FSIS policy changes. Source: FSIS administrative data.

effects of disclosure from other FSIS policy actions and other economic forces that may have affected performance on Salmonella tests.

We construct various empirical models in which we regress economic and policy variables on measures of plant performance on Salmonella tests. We focus on changes in outcomes across three policy periods
(2004-2010, 2006-2010, and 2008-2010) during which different sets of FSIS actions and policies were effective. The exogenous FSIS policy actions included disclosure policies affecting only chicken-slaughter plants and other actions directed at all slaughter and ground meat plants. Ideally, we would contrast the test performance of chicken-slaughter plants affected by disclosure policies with 
unaffected chicken plants. However, there is no control group because all but the tiniest of plants are federally inspected by FSIS. We accommodate these concerns by using the timing of FSIS policy actions and a model that accounts for exogenous events, plant characteristics, and food-safety process controls.

The data are comprehensive but do not include information about customers. Yet, contracts between chicken buyers and sellers have been a feature of purchase arrangements for many years. Ollinger, Moore, and Chandran (2004) indicated that about two-thirds of chicken slaughter plants had contracts with buyers that included standards stricter than those imposed by FSIS in 2000, when our study period begins. Ollinger and Moore (2008) found that these contracts were associated with better performance on Salmonella tests. Together, these findings suggest that contracts for food safety were being used before our study period began in 2000 , and that customers can influence safety outcomes. We therefore incorporate plant-level fixed effects into our econometric model.

Customer demand for food safety can change over time as exogenous events influence customer awareness of the threats to public health posed by insufficient food safety. To account for changes in customer demand for food safety, we include regressors that reflect available public information about food safety (the number of Salmonella-related recalls of meat and poultry products in the previous year and the number of media reports mentioning Salmonella in chicken products in the current and previous year). ${ }^{8}$ We also include the farm-to-wholesale price spread to account for market conditions.

We examine the impact of public disclosure on Salmonella test performance outcomes with four empirical tests. Each test uses the same framework. The dependent variables measure performance on Salmonella tests. The variables of interest are binary variables representing each FSIS policy action and interactions between these binary variables and a second set of binary variables that indicate plant performance on Salmonella tests in the previous testing year. (Henceforth, the variables Cat 1, Cat 2, and Cat 3 will refer to performance on Salmonella tests in the previ-

\footnotetext{
8 The number of media reports variable was tabulated from Nexis Uni search results for "Salmonella and chicken and not eggs" over entire years.
}

ous testing year and match the definitions for the Categories 1, 2, and 3 established by FSIS in 2006. $)^{9}$ The variables representing FSIS policy actions in 2004, 2006, and 2008 are defined as one from the year of the action $(2004,2006$, or 2008) until 2010. With this specification, we assume that any impacts of FSIS actions are intransient-for instance, effects of the 2006 policy change are still present in 2010 . We reason that plants make long-run investments in food safety that add to the capital stock and form a new baseline of food-safety technology, and that plants would not likely revert to a lower level of investment if a proposed policy is not rapidly implemented because $(a)$ it is costly to change manufacturing practices, $(b)$ there are likely marketing benefits of having better food safety, and (c) there would be a lingering threat of disclosure. Moreover, as discussed by FSIS in the 2006 FR, once plants have adopted an effective food-safety system, they tend to maintain a high level of foodsafety performance and do not revert to weaker performance.

We also control for industry effects, plant characteristics, and process-control variables. All models are detrended to account for technological and other time-varying changes that may affect performance on Salmonella tests. Models also control for plant-level fixed effects. ${ }^{10}$

Plant characteristics variables included in the model are the number of chickens slaughtered, plant age in years, and three dummy variables indicating whether the plant slaughtered animal species other than chickens, cooked, or in any way further processed chicken, thereby diminishing the need for strict control over harmful pathogens, and was part of a multiplant firm. Most of these have been found to

\footnotetext{
9 The FSIS did not begin categorizing plants using the numeric system until 2006, so to maintain consistency across all years of our analysis, we use the thresholds for categorization as they were effective in 2006-2010 and analyze plants' performance on Salmonella tests for the entire year. For the rest of this article, we use the following shorthand terminology: Cat 1 indicates annual performance on Salmonella tests at or better than the Category 1 standard of 6 positive samples out of a 51 -sample set $(11.76 \%$ or lower); Cat 2 indicates annual performance on Salmonella tests of greater than 6 but less than 12 positive samples out of a 51 -sample set $(11.77 \%$ to $23.52 \%)$; and Cat 3 indicate performance on Salmonella tests worse than the Category 2 standard (23.53\% or higher).

${ }^{10}$ We used fixed rather than random effects to avoid making strong assumptions about the correlation of observed and unobserved variables; unobserved and observed variables are assumed to be uncorrelated in random effects models but not in fixed effects models (Allison and Christakis 2006). Note that each plant must have at least two observations and must change at least once; otherwise, all observations associated with the plant are dropped (Allison 2009).
} 
be correlated with performance on tests for Salmonella (Muth et al. 2007; Ollinger and Moore 2008, 2009; Ollinger and Bovay 2018). Three process control variables include each plant's annual shares of HACCP tasks and pre-operational, and operational SSOP tasks in compliance with FSIS standards.

Our first set of empirical tests are linear regressions with plant-level fixed effects, with annual average Salmonella test performance, $S_{i t}$, as the dependent variable, as described in equation (1) as follows:

$$
\begin{aligned}
S_{i t}= & \boldsymbol{\beta} \boldsymbol{x}_{i t}+\boldsymbol{\rho} \boldsymbol{r}_{t}+\boldsymbol{\theta} \tilde{\mathbf{s}}_{i t}+\boldsymbol{\eta} \boldsymbol{y}_{t}+\boldsymbol{\alpha} \tilde{\mathbf{s}}_{i t} \boldsymbol{r}_{t} \\
& +\gamma t+\mu_{i}+\varepsilon_{i t}
\end{aligned}
$$

where $\boldsymbol{x}_{i t}$ is a vector of plant characteristics and variables indicating compliance with processcontrol tasks, as discussed above; $\boldsymbol{r}_{\boldsymbol{t}}$ is a vector of three dummy variables indicating the FSIS policy actions on Salmonella implemented in 2004, 2006, and 2008; $\tilde{\boldsymbol{s}}_{i t}$ is a vector of the two dummy variables Cat 2 and Cat $3 ; \boldsymbol{y}_{t}$ is a vector representing possible demand shifters: the number of recalls for Salmonella in meat and poultry in year $t-1$, the number of media reports mentioning Salmonella, and the farmto-wholesale price spread; $t$ is the time trend, $\mu_{i}$ represents plant fixed effects, and $\varepsilon_{i t}$ is the residual. Because FSIS actions affect all regulated plants exogenously, there are no sample selection issues.

About $11 \%$ of the observations of plantlevel annual Salmonella test results are (truncated at) zero, introducing some heteroskedasticity in the error term. Thus, as a robustness check, we also use a panel tobit model (Honoré 1992) with plant-level fixed effects. ${ }^{11}$ One advantage of the Honoré (1992) tobit model is that it corrects the bias inherent in fixed-effects models that use maximum likelihood estimation and yields consistent estimates. However, as with other nonlinear models, the coefficients of interaction terms cannot be interpreted as marginal effects (Norton, Wang, and Ai 2004). The form of the regression specification is cumbersome and not shown, but uses share $_{i t}$ as the

\footnotetext{
11 Although the dependent variable is not censored - an observation of zero positive Salmonella samples always represents the actual count-the share of Salmonella samples positive can be thought of as a proxy for a latent variable representing the underlying distribution of food-safety risks. That is, there is some distribution of food-safety risks within the set of plants with zero positive Salmonella samples in any given year.
}

dependent variable and the regressors in equation (1).

The first set of empirical specifications allows us to estimate the effects of FSIS policy actions on the share of samples testing positive for Salmonella but does not allow us to assess whether the policy changes affected the likelihood of plants meeting the Cat 1 standard. In a second series of regressions, we regress the same independent variables as in equation (1) on a binary dependent variable equal to one if the plant met the Cat 1 standard. We use a linear probability model with fixed effects, and for robustness we also use a logit regression with fixed effects (Chamberlain 1980; Cameron and Trivedi 2005). ${ }^{12}$

Plants in the chicken-slaughter industry have varying levels of performance on Salmonella tests. These differences may be explained by buyer demands (Ollinger, Moore, and Chandran 2004) and plant policies and objectives. Golan et al. (2004) showed that Texas American Beef used superior food safety performance as a way to distinguish itself from competitors and Dulleck, Kerschbamer, and Sutter (2011) report that one-fourth of vendors in their study provided appropriate service under conditions in which moral hazard thrived. Below, we use two empirical tests to examine how plants responded differentially to the FSIS policy actions.

In the first test, we evaluate a series of linear probability models with binary dependent variables defined as one if the plant met one of several hypothetical standards more stringent than the FSIS standard. This allows us to examine whether FSIS actions motivated better performance than the standard mandated by FSIS.

In the second test, we evaluate how different types of chicken slaughter plants may have responded differently to FSIS actions. Reasoning that plants would incur the costs of attaining consistently strong performance on Salmonella tests only if customer demand or plant-level goals for food safety required it, we split the data into three groups of plants distinguished by their performance on Salmonella tests prior to any FSIS actions, that is, over 2000-2003

\footnotetext{
12 The disadvantages of a linear probability model include that predictions can fall outside the unit interval and the error term is heteroskedastic (Wooldridge 2009). The advantage is that marginal effects are easy to interpret because they are linear (Stock and Watson 2011). Simple logit models accommodate discrete data, but fixed-effects logit models are biased (Greene 2003); thus, we use a conditional fixed-effects logit because it gives unbiased estimates by conditioning the number of groups out of the likelihood function (Allison and Christakis 2006). However, the coefficients on interaction terms are unreliable and log-odds ratios are difficult to interpret (Norton, Wang, and Ai 2004).
} 
Table 2. Number of Plant Observations Meeting Categories 1, 2, and 3 Levels of Performance over 2000-2010 by Regulatory Period and Performance before 2004

\begin{tabular}{|c|c|c|c|c|c|c|}
\hline \multirow[b]{3}{*}{ Years } & \multicolumn{5}{|c|}{ Type of Performance before 2004} & \multirow{3}{*}{$\begin{array}{c}\text { All Types } \\
\text { (6) }\end{array}$} \\
\hline & \multirow{2}{*}{$\begin{array}{c}\text { Good } \\
100 \\
(1)\end{array}$} & \multirow{2}{*}{$\begin{array}{c}\text { Intermediate } \\
\text { Percent Cat } 1 \\
50-100 \\
(2)\end{array}$} & \multicolumn{2}{|c|}{$\begin{array}{l}\text { Poor Strong } \\
\text { ting before } 2004\end{array}$} & \multirow{2}{*}{$\begin{array}{c}\text { Weak } \\
<75 \\
(5)\end{array}$} & \\
\hline & & & $\begin{array}{l}<50 \\
(3)\end{array}$ & $\begin{array}{l}\geq 75 \\
(4)\end{array}$ & & \\
\hline \multicolumn{7}{|c|}{ Number of Observations Cat 1} \\
\hline $2000-03$ & 173 & 127 & 51 & 269 & 82 & 351 \\
\hline $2004-05$ & 66 & 39 & 51 & 92 & 64 & 156 \\
\hline 2006-07 & 66 & 45 & 71 & 97 & 85 & 182 \\
\hline 2008-10 & 94 & 78 & 91 & 147 & 116 & 263 \\
\hline \multicolumn{7}{|l|}{ Number of Observations Cat 2} \\
\hline $2000-03$ & 0 & 40 & 102 & 25 & 117 & 142 \\
\hline $2004-05$ & 30 & 28 & 46 & 52 & 52 & 104 \\
\hline 2006-07 & 14 & 15 & 15 & 26 & 18 & 44 \\
\hline 2008-10 & 10 & 8 & 11 & 17 & 12 & 29 \\
\hline \multicolumn{7}{|c|}{ Number of Observations Cat 3} \\
\hline $2000-03$ & 0 & 10 & 33 & 5 & 38 & 43 \\
\hline $2004-05$ & 12 & 8 & 12 & 17 & 15 & 32 \\
\hline $2006-07$ & 6 & 2 & 2 & 8 & 2 & 10 \\
\hline $2008-10$ & 0 & 2 & 3 & 2 & 3 & 5 \\
\hline Total observations, all Cats & 471 & 402 & 488 & 757 & 604 & 1,361 \\
\hline
\end{tabular}

(table 2), and examined the performance of those subgroups of plants on Salmonella tests.

\section{Results}

We first present empirical evidence of the effects of FSIS policy actions on the Salmonella test performance of chicken-slaughter plants using linear regressions with plant-level fixed effects and panel tobit regressions. Then, we show how FSIS policy actions affected the likelihood of chicken-slaughter plants meeting or overcomplying with the Cat 1 standard. Finally, we demonstrate the effects of policy changes on the test performance of the good, intermediate, and poor performance subgroups. The key variables in our regressions are three binary variables for three regulatory periods, and the interactions of these regulatory variables with Salmonella threshold variables (Cat 2 and Cat 3).

\section{Effects on Average Salmonella Test Results}

Table 3 presents the results of the linear and panel tobit regressions with plant fixed effects; the share of positive Salmonella test results is the dependent variable. Any unchanging plant manager or buyer effects that may impact Salmonella test outcomes are captured by the plant fixed effects variables. Results show that the first FSIS actions in 2003 and 2004 had small effects. Cat 3 plants, which failed Salmonella testing the year before and were already subject to increased scrutiny, had 5 percentage-point reductions in the number of samples testing positive for Salmonella, relative to the reference group (Cat 1 plants). FSIS actions starting in 2006 and 2008 had much larger effects as the number of samples testing positive for Salmonella dropped by 6 to 10 percentage points after 2005 , and by another 3 to 5 percentage points after 2007, compared with the periods immediately prior. The number of positive test samples at Cat 2 plants was about 4 percentage points higher than at Cat 1 plants throughout 2000-2010; there was no significant difference between Cat 1 and Cat 3 plants.

Hog-slaughter and ground-beef plants were affected by FSIS actions dealing with regulatory stringency in 2004 and 2006 but not disclosure, and offer a contrast to chicken slaughter. Results provide no evidence that FSIS actions had an effect on Salmonella in ground beef and hog slaughter. However, these results (see online supplementary table A.4) can only be considered as suggestive and not strongly identified because the three industries use different 
Table 3. Effects of Past Performance and FSIS Policy Changes on Performance of Young-Chicken Slaughter Plants on Tests for Salmonella, 2000-2010 (Share of Samples Positive)

\begin{tabular}{|c|c|c|c|c|}
\hline & \multicolumn{2}{|c|}{ Linear Regression } & \multicolumn{2}{|c|}{ Panel Tobit Regression } \\
\hline & (1) & (2) & (3) & (4) \\
\hline \multirow[t]{2}{*}{ Post-2003 } & 0.00338 & 0.00268 & $-3.77 \times 10^{-5}$ & -0.00112 \\
\hline & $(0.0124)$ & $(0.0125)$ & $(0.0148)$ & $(0.0152)$ \\
\hline \multirow[t]{2}{*}{ Post-2005 } & $-0.0613 * * *$ & $-0.0824 * * *$ & $-0.0734 * * *$ & $-0.101 * * *$ \\
\hline & $(0.0170)$ & $(0.0235)$ & $(0.0213)$ & $(0.0287)$ \\
\hline \multirow[t]{2}{*}{ Post-2007 } & $-0.0339 * * *$ & $-0.0385 * * *$ & $-0.0447 * * *$ & $-0.0491 * * *$ \\
\hline & $(0.0121)$ & $(0.0139)$ & $(0.0157)$ & $(0.0178)$ \\
\hline \multirow[t]{2}{*}{ Cat 2} & $0.0354 * * *$ & $0.0350 * * *$ & $0.0379 * * *$ & $0.0368 * * *$ \\
\hline & $(0.0106)$ & $(0.0113)$ & $(0.0130)$ & $(0.0138)$ \\
\hline \multirow{2}{*}{ Cat 3} & 0.00831 & 0.00798 & 0.00578 & 0.00549 \\
\hline & $(0.0142)$ & $(0.0151)$ & $(0.0160)$ & $(0.0176)$ \\
\hline \multirow[t]{2}{*}{ Cat $2 \times$ Post -2003} & -0.0100 & -0.00752 & -0.0130 & -0.00872 \\
\hline & $(0.0151)$ & $(0.0155)$ & $(0.0176)$ & $(0.0180)$ \\
\hline \multirow{2}{*}{ Cat $2 \times$ Post -2005} & -0.0208 & -0.0224 & -0.0179 & -0.0204 \\
\hline & $(0.0181)$ & $(0.0190)$ & $(0.0214)$ & $(0.0224)$ \\
\hline \multirow[t]{2}{*}{ Cat $2 \times$ Post- 2007} & 0.00997 & 0.00638 & 0.0175 & 0.0130 \\
\hline & $(0.0181)$ & $(0.0183)$ & $(0.0225)$ & $(0.0224)$ \\
\hline \multirow[t]{2}{*}{ Cat $3 \times$ Post -2003} & $-0.0503 * *$ & $-0.0476^{*}$ & $-0.0542 * *$ & $-0.0508^{*}$ \\
\hline & $(0.0244)$ & $(0.0246)$ & $(0.266)$ & $(0.0271)$ \\
\hline \multirow[t]{2}{*}{ Cat $3 \times$ Post -2005} & -0.00123 & -0.00508 & 0.00177 & -0.00338 \\
\hline & $(0.0285)$ & $(0.0300)$ & $(0.0328)$ & $(0.0355)$ \\
\hline \multirow[t]{2}{*}{ Cat $3 \times$ Post -2007} & 0.0441 & 0.0391 & 0.0433 & 0.0346 \\
\hline & $(0.0594)$ & $(0.0574)$ & $(0.0845)$ & $(0.0762)$ \\
\hline \multirow[t]{2}{*}{ Media reports } & $-1.30 \times 10^{-5}$ & $-3.82 \times 10^{-6}$ & $-1.97 \times 10^{-5 *}$ & $-6.29 \times 10^{-6}$ \\
\hline & $\left(8.05 \times 10^{-6}\right)$ & $\left(8.83 \times 10^{-6}\right)$ & $\left(1.09 \times 10^{-5}\right)$ & $\left(1.18 \times 10^{-5}\right)$ \\
\hline Lag number of Salmonella & $-0.00671 * * *$ & $-0.00852 * * *$ & $-0.00866 * * *$ & $-0.0109 * * *$ \\
\hline recalls & $(0.00225)$ & $(0.00258)$ & $(0.00288)$ & $(0.00325)$ \\
\hline \multirow[t]{2}{*}{ Trend } & $0.00646^{*}$ & $0.0106^{* *}$ & $0.00800 * *$ & $0.0132 * * *$ \\
\hline & $(0.00337)$ & $(0.00404)$ & $(0.00397)$ & $(0.00481)$ \\
\hline Plant Characteristics & No & Yes & No & Yes \\
\hline Process Controls & No & Yes & No & Yes \\
\hline Constant & $0.125 * * *(0.0199)$ & $0.183 * * *(0.0420)$ & - & - \\
\hline Observations & 1,361 & 1,295 & 1,361 & 1,295 \\
\hline & & & $154.92 * * *$ & $209.93 * * *$ \\
\hline Share of observations censored & & & 0.11 & 0.11 \\
\hline
\end{tabular}

Note: Dependent variable is the share of samples positive for Salmonella. Plant-level cluster-robust standard errors are in parentheses. Single, double, and triple asterisks $(*, * *, * *)$ represent significance at the $10 \%, 5 \%$, and $1 \%$ levels, respectively. All columns also include a regressor for farm-to-wholesale price spread (not statistically significant). See online supplementary table A.3 for values for plant characteristic and process control controls.

technologies and have different trends in their shares of samples testing positive for Salmonella, a violation of the parallel trends assumption necessary for difference-in-difference analyses (see the online supplementary appendix).

\section{Effects on Compliance and Overcompliance with FSIS Salmonella Standards}

In columns 1 and 2 of table 4, we present results from a linear probability model with the dependent variable equaling 1 if plants met the Cat 1 standard. These results show that Cat 2 plants were 12 to 13 percentage points more likely to meet the Cat 1 standard beginning in 2004; Cat 3 plants were no more likely to meet the Cat 1 standard, although they did have a significant improvement in test performance as shown in table 3. Other results are consistent with those for the linear and tobit regressions (table 3), and indicate that the likelihood of meeting the Cat 1 standard rose 35 to 41 percentage points for all plants beginning in 2006 and an additional 14 to 16 percentage points beginning in 2008. After accounting for a declining linear time trend of 3 to 5 percentage points and all interaction effects, the net effect was that Cat 1 plants were 31 to 32 percentage points more likely to meet the Cat 1 standard in 2010 than 
Table 4. Effects of Past Performance and FSIS Policy Changes on Likelihood of Young-Chicken Slaughter Plants Meeting Cat 1 Standard on Tests for Salmonella, 2000-2010

\begin{tabular}{|c|c|c|c|c|}
\hline & \multicolumn{2}{|c|}{$\begin{array}{c}\text { Linear Probability Model, } \\
\text { Plant Fixed Effects }\end{array}$} & \multicolumn{2}{|c|}{$\begin{array}{l}\text { Conditional Logit Regression, } \\
\text { Plant Fixed Effects } \\
\text { (Odds Ratios) }\end{array}$} \\
\hline & $(1)$ & (2) & (3) & (4) \\
\hline Post-2003 & $\begin{array}{l}-0.0247 \\
(0.0675)\end{array}$ & $\begin{array}{l}-0.0247 \\
(0.0689)\end{array}$ & $\begin{array}{c}0.937 \\
(0.337)\end{array}$ & $\begin{array}{c}0.893 \\
(0.313)\end{array}$ \\
\hline Post-2005 & $\begin{array}{l}0.347 * * * \\
(0.0925)\end{array}$ & $\begin{array}{c}0.414 * * * \\
(0.121)\end{array}$ & $\begin{array}{c}6.81 * * * \\
(3.64)\end{array}$ & $\begin{array}{c}9.94 * * * \\
(6.99)\end{array}$ \\
\hline Post-2007 & $\begin{array}{l}0.142 * * \\
(0.0584)\end{array}$ & $\begin{array}{l}0.161^{* *} \\
(0.0671)\end{array}$ & $\begin{array}{l}2.86 * * \\
(1.29)\end{array}$ & $\begin{array}{l}2.88 * * \\
(1.43)\end{array}$ \\
\hline Cat 2 & $\begin{array}{c}-0.154 * * * \\
(0.0501)\end{array}$ & $\begin{array}{l}-0.146 * * * \\
(0.0523)\end{array}$ & $\begin{array}{l}0.600 * * \\
(0.134)\end{array}$ & $\begin{array}{l}0.613 * * \\
(0.145)\end{array}$ \\
\hline Cat 3 & $\begin{array}{c}0.0290 \\
(0.0791)\end{array}$ & $\begin{array}{c}0.0133 \\
(0.0796)\end{array}$ & $\begin{array}{l}1.34 \\
(0.490)\end{array}$ & $\begin{array}{l}1.24 \\
(0.469)\end{array}$ \\
\hline Cat $2 \times$ Post -2003 & $\begin{array}{c}0.130 * \\
(0.0724)\end{array}$ & $\begin{array}{c}0.116 \\
(0.0726)\end{array}$ & $\begin{array}{l}1.91 * \\
(0.677)\end{array}$ & $\begin{array}{l}1.84 * \\
(0.665)\end{array}$ \\
\hline Cat $2 \times$ Post -2005 & $\begin{array}{c}0.0432 \\
(0.0881)\end{array}$ & $\begin{array}{c}0.0445 \\
(0.0935)\end{array}$ & $\begin{array}{c}0.865 \\
(0.453)\end{array}$ & $\begin{array}{c}0.873 \\
(0.505)\end{array}$ \\
\hline Cat $2 \times$ Post- 2007 & $\begin{array}{l}-0.0249 \\
(0.0809)\end{array}$ & $\begin{array}{l}0.00249 \\
(0.0841)\end{array}$ & $\begin{array}{c}0.655 \\
(0.346)\end{array}$ & $\begin{array}{c}0.741 \\
(0.411)\end{array}$ \\
\hline Cat $3 \times$ Post- 2003 & $\begin{array}{c}0.107 \\
(0.133)\end{array}$ & $\begin{array}{l}0.105 \\
(0.131)\end{array}$ & $\begin{array}{l}2.05 \\
(1.21)\end{array}$ & $\begin{array}{c}1.99 \\
(1.14)\end{array}$ \\
\hline Cat $3 \times$ Post -2005 & $\begin{array}{c}-0.0112 \\
(0.138)\end{array}$ & $\begin{array}{l}0.0150 \\
(0.144)\end{array}$ & $\begin{array}{c}0.697 \\
(0.509)\end{array}$ & $\begin{array}{c}0.842 \\
(0.649)\end{array}$ \\
\hline Cat $3 \times$ Post-2007 & $\begin{array}{l}-0.104 \\
(0.251)\end{array}$ & $\begin{array}{c}-0.0714 \\
(0.235)\end{array}$ & $\begin{array}{c}0.382 \\
(0.604)\end{array}$ & $\begin{array}{c}0.514 \\
(0.696)\end{array}$ \\
\hline Media reports & $\begin{array}{c}5.90 \times 10^{-5} \\
\left(4.28 \times 10^{-5}\right)\end{array}$ & $\begin{array}{c}1.48 \times 10^{-5} \\
\left(4.65 \times 10^{-5}\right)\end{array}$ & $\begin{array}{c}1.000^{*} \\
(0.000359)\end{array}$ & $\begin{array}{c}1.000 \\
(0.000361)\end{array}$ \\
\hline Lag number of Salmonella recalls & $\begin{array}{c}0.0318 * * * \\
(0.0110)\end{array}$ & $\begin{array}{c}0.0392 * * * \\
(0.0120)\end{array}$ & $\begin{array}{l}1.25 * * * \\
(0.0830)\end{array}$ & $\begin{array}{l}1.30 * * * \\
(0.0954)\end{array}$ \\
\hline Trend & $\begin{array}{l}-0.0336^{*} \\
(0.0174)\end{array}$ & $\begin{array}{c}-0.0523 * * \\
(0.0210)\end{array}$ & $\begin{array}{c}0.839 * \\
(0.0761)\end{array}$ & $\begin{array}{l}0.762 * * \\
(0.0882)\end{array}$ \\
\hline Plant Characteristics & No & Yes & No & Yes \\
\hline Process Controls & No & Yes & No & Yes \\
\hline Constant & $0.532(0.109)$ & $0.315(0.199)$ & - & - \\
\hline Observations & 1,361 & 1,295 & 1,183 & 1,120 \\
\hline
\end{tabular}

Note: Dependent variable is the likelihood of meeting the Cat 1 standard for Salmonella. Plant-level cluster-robust standard errors are in parentheses. Single, double, and triple asterisks $(*, * *, * *)$ represent significance at the $10 \%, 5 \%$, and $1 \%$ levels, respectively. All columns also include a regressor for

farm-to-wholesale price spread (not statistically significant). See online supplementary table A.4 for values for plant characteristic and process control controls.

in 2005. Other results show that Cat 2 plants were consistently less likely than either Cat 1 or Cat 3 plants to attain the Cat 1 standardagain, suggesting that managers worked to avoid Cat 3 outcomes but not Cat 2 outcomes. The conditional logit results (columns 3 and 4) are reported as odds ratios with plant-level clustered standard errors in parentheses and are consistent with the linear probability results, showing that results are insensitive to the form of the regression. ${ }^{13}$

\footnotetext{
${ }^{13}$ Odds ratios greater than 1 indicate a greater likelihood of meeting the Cat 1 standard.
}

The FSIS encouraged plants to meet the Category 1 standard but some plants may have been encouraged to overcomply to meet customer demands or ensure against risks. Using linear probability models, we evaluate the effects of FSIS policy actions on the likelihood that plants met hypothetical standards more stringent than Category 1 . The models are of the same form as in equation (1), but with binary variables indicating whether the plant had annual average test results less than or equal to 4, 2, and 1 out of 51 samples positive. Results are given in online supplementary table A.5. Cat 1 (reference group) plants were 13 to 16 percentage points less likely to meet 
Table 5. Effects of Past Performance and FSIS Policy Changes on Performance of Subgroups of Young-Chicken Slaughter Plants on Tests for Salmonella, 2000-2010 (Share of Samples Positive)

\begin{tabular}{|c|c|c|c|c|c|c|}
\hline & \multicolumn{6}{|c|}{ Performance before 2004} \\
\hline & \multicolumn{2}{|c|}{ Good } & \multicolumn{2}{|c|}{ Intermediate } & \multicolumn{2}{|c|}{ Poor } \\
\hline & (1) & (2) & (3) & (4) & $(5)$ & (6) \\
\hline Post-2003 & $\begin{array}{c}0.0586 * * * \\
(0.0156)\end{array}$ & $\begin{array}{c}0.0577 * * * \\
(0.0162)\end{array}$ & $\begin{array}{l}-0.00965 \\
(0.0235)\end{array}$ & $\begin{array}{l}-0.00496 \\
(0.0228)\end{array}$ & $\begin{array}{c}-0.0508^{*} \\
(0.0258)\end{array}$ & $\begin{array}{c}-0.0538 * * \\
(0.0240)\end{array}$ \\
\hline Post-2005 & $\begin{array}{c}-0.0672 * * * \\
(0.0215)\end{array}$ & $\begin{array}{c}-0.0746^{* *} \\
(0.0321)\end{array}$ & $\begin{array}{c}-0.0788 * * \\
(0.0329)\end{array}$ & $\begin{array}{l}-0.114 * * \\
(0.0431)\end{array}$ & $\begin{array}{c}-0.0667 * * * \\
(0.0243)\end{array}$ & $\begin{array}{c}-0.0794 * * \\
(0.0332)\end{array}$ \\
\hline Post-2007 & $\begin{array}{c}-0.0397 * * \\
(0.0153)\end{array}$ & $\begin{array}{c}-0.0412 * * \\
(0.0181)\end{array}$ & $\begin{array}{c}-0.0618^{* *} \\
(0.0230)\end{array}$ & $\begin{array}{c}-0.0637 * * \\
(0.0272)\end{array}$ & $\begin{array}{l}0.00135 \\
(0.0198)\end{array}$ & $\begin{array}{l}0.00106 \\
(0.0226)\end{array}$ \\
\hline Cat 2 & $\begin{array}{c}0.00823 \\
(0.00989)\end{array}$ & $\begin{array}{l}0.00685 \\
(0.0108)\end{array}$ & $\begin{array}{c}0.00387 \\
(0.00998)\end{array}$ & $\begin{array}{l}0.00690 \\
(0.0104)\end{array}$ & $\begin{array}{c}0.0203 \\
(0.0177)\end{array}$ & $\begin{array}{l}0.0202^{*} \\
(0.0121)\end{array}$ \\
\hline Cat 3 & $\begin{array}{c}-0.0679 * * * \\
(0.0179)\end{array}$ & $\begin{array}{c}-0.0698 * * * \\
(0.0184)\end{array}$ & $\begin{array}{l}-0.0113 \\
(0.0192)\end{array}$ & $\begin{array}{l}-0.0212 \\
(0.0191)\end{array}$ & $\begin{array}{c}-0.0295^{*} \\
(0.0161)\end{array}$ & $\begin{array}{l}-0.0299 * \\
(0.00170)\end{array}$ \\
\hline Media reports & $\begin{array}{l}(1.28 \\
\left.\times 10^{-5}\right)\end{array}$ & $\begin{array}{l}(1.51 \\
\left.\times 10^{-5}\right)\end{array}$ & $\begin{array}{l}- \\
1.58 \\
\times 10^{-5} \\
(1.79 \\
\left.\times 10^{-5}\right)\end{array}$ & $\begin{array}{l}(1.77 \\
\left.\times 10^{-5}\right)\end{array}$ & $\begin{array}{c}2.45 \\
\times 10^{-5 * * *} \\
\left(1.23 \times 10^{-5}\right)\end{array}$ & $\begin{array}{l}(1.39 \\
\left.\times 10^{-5}\right)\end{array}$ \\
\hline $\begin{array}{l}\text { Lag number of Salmonella } \\
\text { recalls }\end{array}$ & $\begin{array}{l}-0.00277 \\
(0.00266)\end{array}$ & $\begin{array}{l}-0.00315 \\
(0.00326)\end{array}$ & $\begin{array}{l}-0.00766^{*} \\
(0.00427)\end{array}$ & $\begin{array}{l}-0.0115^{* *} \\
(0.00493)\end{array}$ & $\begin{array}{c}-0.00834 * * \\
(0.00400)\end{array}$ & $\begin{array}{c}-0.00981^{* *} * \\
(0.00425)\end{array}$ \\
\hline Trend & $\begin{array}{c}0.00521 \\
(0.00447)\end{array}$ & $\begin{array}{c}0.00468 \\
(0.00534)\end{array}$ & $\begin{array}{l}0.0148 * * \\
(0.00721)\end{array}$ & $\begin{array}{l}0.0219 * * \\
(0.00850)\end{array}$ & $\begin{array}{l}-0.00165 \\
(0.00607)\end{array}$ & $\begin{array}{l}0.00422 \\
(0.0066)\end{array}$ \\
\hline $\begin{array}{l}\text { Number of chickens } \\
\text { slaughtered }\end{array}$ & - & $\begin{array}{c}0.000546 \\
(0.000646)\end{array}$ & - & $\begin{array}{l}-0.000469 \\
(0.000691)\end{array}$ & - & $\begin{array}{r}-0.00111 * * \\
(0.000478)\end{array}$ \\
\hline Multi-species & - & $\begin{array}{c}0.0118 \\
(0.00950)\end{array}$ & - & $\begin{array}{l}0.0481 * \\
(0.0281)\end{array}$ & - & $\begin{array}{c}0.0152 \\
(0.0160)\end{array}$ \\
\hline Age of plant & - & $\begin{array}{l}0.00172 * * \\
(0.000654)\end{array}$ & - & $\begin{array}{c}-0.00192 \\
(0.124)\end{array}$ & - & $\begin{array}{l}-0.000581 \\
(0.000722)\end{array}$ \\
\hline $\begin{array}{l}\text { Pre-operational SSOP } \\
\text { compliance }\end{array}$ & - & $\begin{array}{l}-0.0807 \\
(0.0555)\end{array}$ & - & $\begin{array}{l}-0.150 * * \\
(0.0710)\end{array}$ & - & $\begin{array}{l}-0.0396 \\
(0.0753)\end{array}$ \\
\hline Constant & $\begin{array}{c}0.0896 * * * \\
(0.0289)\end{array}$ & $\begin{array}{c}0.0442 \\
(0.0536)\end{array}$ & $\begin{array}{c}0.135 * * * \\
(0.0453)\end{array}$ & $\begin{array}{l}0.251 * * \\
(0.098)\end{array}$ & $\begin{array}{c}0.191 * * * \\
(0.0266)\end{array}$ & $\begin{array}{l}0.275 * * * \\
(0.0571)\end{array}$ \\
\hline Observations & 471 & 443 & 402 & 385 & 488 & 467 \\
\hline
\end{tabular}

Note: Plant-level cluster-robust standard errors in parentheses. Single, double, and triple asterisks $(*, * *, * * *)$ represent significance at the $10 \%, 5 \%$, and $1 \%$ levels, respectively. Good plants have Cat 1 performance in all years before 2004; Poor plants have Cat 1 performance in $50 \%$ or less of years before 2004 ; Intermediate plants are not in Good or Poor groups. All columns also include a regressor for deflated farm-to-wholesale price spread (not statistically significant). Columns (2), (4), and (6) also include the following regressors (not statistically significant in any regression): binary variables that indicate whether a plant is part of a multi-plant firm and whether a plant further processes chicken; shares of operational SSOP and HACCP tasks in compliance. Multi-species is a binary variable defined as one if a chicken-slaughter plant butchers turkeys or other poultry.

the $2 / 51$ and $1 / 51$ thresholds over 2004-2010 compared with the previous period, but 23 to 37 percentage points more likely to meet the various thresholds over 2006-2010 (compared with the 2004-2005 period) and an additional 13 to 27 percentage points more likely to meet the thresholds over 2008-2010 (compared with the 2006-2007 period).

Overall, Cat 2 and Cat 3 plants were 9 to 19 percentage points less likely to meet the $4 / 51,2 / 51$, and $1 / 51$ standards than Cat 1 plants. However, after the first FSIS policy actions in 2003 and 2004, Cat 3 plants became substantially more likely to meet hypothetical standards. In other words, the only plants that were directly affected by the initial FSIS policy announcements (Cat 3 plants) became more likely to overcomply over 2004-2005. Cat 2 plants became as likely as Cat 1 plants to meet the 2/51 and 1/51 standards after 2003. Significant covariates include $(a)$ improved Salmonella test results in years after recalls for Salmonella, $(b)$ worse performance by plants that slaughter multiple species, $(c)$ better performance by larger plants, and $(d)$ slightly improved Salmonella test results when the farm-to-wholesale price spread for was higher. 


\section{Policy Changes and Salmonella Test Performance of Good and Poor Performance Subgroups}

Differences in business strategies, manager choices, and customer demands influence food safety process control decisions. To examine the heterogeneous responses of producers that may have had different Salmonella control priorities before FSIS policy actions, we split the sample of plants into groups (table 2) based on performance on Salmonella tests before 2004. Good performance plants always met the Cat 1 standards, meaning that they would have been less sensitive to changes in regulatory stringency than Poor performance plants, which frequently failed to meet the FSIS standard. On the other hand, since Good performance plants may have catered to buyers' demands that they meet stringent safety standards, they likely would have responded more strongly to disclosure policies than Poor performance plants.

Table 5 shows regression results for Good-, Intermediate-, and Poor-performance plants. ${ }^{14}$ Interaction effects between the period and category dummies are not included because many cells have too few observations (table 2). Results show that Good-performance plants had an increase in the share of samples testing positive for Salmonella after 2003, while Poorperformance plants had improved, reducing the share of samples testing positive by about 5 percentage points. Each group had improved performance after 2005, and all groups had a net improvement in performance based on the first two announcements (see the coefficients on the Post-2003 and Post-2005 binary variables). Poor-performance plants, the ones most susceptible to regulatory stringency, had the greatest improvement and Goodperformance plants the least.

The FSIS threatened disclosure of the names of Category 2 and Category 3 plants in 2006 and implemented a disclosure policy in 2008. After 2007, the Good and Intermediate plants had reductions of 4 to 6 percentage points in their shares of samples testing positive for Salmonella, while the Poor plants had statistically insignificant reductions. After the 2006 and 2008 FSIS actions (coefficients on the Post-2005 and Post-2007 binary variables), when public disclosure was threatened and

\footnotetext{
${ }^{14}$ For robustness, we also split the observations into two subgroups labeled Strong- and Weak-performance plants. The results of these regressions are presented in online appendix table A.5.
}

implemented, all five subgroups (see tables 5 and online supplementary table A.6) had reductions in the number of samples testing positive for Salmonella of 7 to 11 percentage points. These results were strongest for Good and Intermediate plants, perhaps the plants most sensitive to disclosure policy. Results also indicate that Good-performance plants bounced back from a Cat 3 performance. Results for Strong and Weak plants (see supplementary table A.6) resemble those for Good and Poor performance plants. Overall, these results suggest that actions dealing with public disclosure are more strongly associated with better performance on Salmonella tests in better-performance plants, and that FSIS actions concerning more stringent regulation are associated with better performance on Salmonella tests in worse-performance plants.

\section{Discussion}

The purpose of this paper was to examine the impact of public disclosure embedded in FSIS actions occurring over 2003-2008 on the performance of chicken-slaughter plants on tests for Salmonella. We could not directly examine the impact of FSIS actions on affected and unaffected plants because all federallyinspected chicken-slaughter plants were affected by the public disclosure policy. As an alternative, we assessed the impacts of policy changes on performance on Salmonella tests by using empirical models that leverage the timing of FSIS policy actions while accounting for factors shown previously to affect performance on Salmonella tests, including exogenous events, plant characteristics, and food-safety process controls. We had no data on customer characteristics, but our fixed-effects econometric model enabled us to control for unchanging plant characteristics such as customer contracts. We controlled for changing market-wide customer demand by including as regressors negative media stories, recalls for Salmonella, and farm-to-wholesale price spreads.

In 2003, FSIS began a dialogue about disclosing the identities of plants with poor performance on Salmonella tests and later implemented this disclosure policy while also imposing stricter regulatory oversight. More specifically, the 2003 action introduced disclosure as a potential policy, but the plan had no specificity and FSIS withdrew it. In 2004, the 
FSIS stated that it would strengthen regulatory oversight of plants performing poorly on Salmonella tests. Regression results showed that only poorly performing plants - the ones most affected by regulatory oversightimproved their performance after 2003. In particular, see the regression results for plants not meeting the FSIS standard in the previous year (Cat 3, table 3) and Poor performance plants (table 5). We therefore attribute the improvements in performance after 2003 to more stringent enforcement of regulation.

In its 2006 FR announcement, the FSIS established the category rating system, imposed stricter oversight of Category 2 and, particularly, Category 3 plants, and enabled better information-sharing of PFGE results. These elements focused on regulatory oversight and applied to all meat- and poultryslaughter and ground-meat plants. Overall, they do not appear to have markedly changed policy. The category rating system gives a concise measure of Salmonella tests performance, but, without disclosure, conveyed information only to FSIS and the plant being tested, both of which already knew their performance. The change in regulatory stringency applied mainly to Category 3 plants, which were failing testing and already the subject of greater regulatory focus as outlined in the 2004 FSIS announcement. Finally, PFGE testing was already widespread by 2006, making the greater sharing of information a marginal improvement.

The 2006 FR announcement focused attention on the chicken-slaughter industry. In this announcement, FSIS expressed concern about levels of Salmonella-related foodborne illnesses and rising levels of Salmonella in chicken carcasses, and stated that disclosure would be forthcoming unless $90 \%$ of the industry met a Category 1 standard. This threat was cited in the 2008 FR when FSIS announced its disclosure policy for the chicken-slaughter industry.

Regression results indicate that the 2006 FSIS policy action did not affect Cat 2 and Cat 3 plants differentially (tables 3 and 4), and, as discussed in the online supplementary appendix, FSIS actions had no effect on the performance on Salmonella tests of plants in the hog-slaughter and ground-beef industries (see online supplementary table A.4). Meanwhile, beginning in 2006, the chickenslaughter industry broadly improved its performance (tables 3 and 4) and all subgroups improved their performance (table 5). These results, combined with the weak nature and lack of novelty of nondisclosure actions, lead to the conclusion that regulatory stringency played a minor role in changes in performance on Salmonella tests after 2005, and that concerns about the impending disclosure policy were at the root of change.

The 2008 FR announcement implemented a policy of public disclosure in the chickenslaughter industry; there was no mention of more stringent regulation. Results show overall improvement on Salmonella tests (Post2007 in tables 3 and 4) and better performance of Good and Intermediate performance plants (table 5). The 2008 policy action had little effect on Cat 2 or Cat 3 plants or Poorperformance plants. We conclude that public disclosure encouraged better performance only among those plants that already maintained good food-safety records.

\section{Implications for Public Welfare and Policy}

Roe and Sheldon (2007) offer some insights of the public welfare effects of more (or less) stringent standards. These authors demonstrate that under a mandatory, exclusive, discrete labeling standard that is set relatively lax, sellers are worse off because competition drives lower prices; buyers who prefer a higher standard of quality are also worse off. ${ }^{15}$ Roe and Sheldon (2007) offer several other examples of labeling standards and conclude that mandatory reporting of continuous quality measures, such as the share of samples testing positive, provides the same outcome as would result under perfect information, making it more efficient than discrete quality standards such as reporting the names of Category 2 and 3 plants.

Contracts specifying food safety have emerged (see, e.g., Ollinger, Moore, and Chandran 2004; Bovay and Sumner 2018) and can match buyers and sellers. However, contracts have transaction costs and do not reduce the information asymmetry problem facing buyers on the spot market. An alternative is for public authorities to publicly disclose food safety quality, for example, performance on Salmonella tests. Buyers demanding higher quality could then be matched with sellers offering higher quality and vice versa. A

\footnotetext{
15 The mandatory, exclusive, discrete standard described by Roe and Sheldon (2007) is slightly different from ours, in that chicken-slaughter plants did not pay for certification as belonging to a particular category.
} 
minimum standard may still be necessary to assure consumers and spot-market buyers that chicken meets a basic level of food safety.

\section{Conclusion}

This article investigated the effects of policy changes that culminated in disclosure of information about the results of tests for Salmonella in chicken carcasses. In 2003, the USDA Food Safety and Inspection Service asked for comments on a proposal to publicly disclose slaughter and ground meat plant performance on tests for Salmonella, and in 2004 announced its intention to impose stricter regulatory oversight of chicken plants failing to meet its Salmonella performance standard. In 2006, the FSIS began categorizing plants by their Salmonella test results, enhanced the sharing of PFGE test data, and increased regulatory oversight of plants with weak performance on Salmonella tests. These changes affected all slaughter and ground-meat plants, but the FSIS expressed special concern about rising levels of Salmonella in chicken carcasses, and persistently high levels of foodborne illnesses associated with Salmonella. The FSIS indicated that it would disclose the identities of plants failing to meet the highest level of performance (Category 1) if industry Salmonella test results did not improve. The disclosure of the names of plants not meeting the Category 1 level began in 2008.

Empirical results indicate that most plants avoided public disclosure by improving performance before public disclosure took place, but some plants failed to meet the standard even after disclosure was implemented. We interpret these results to mean that most buyers expect the best food safety performance but may accept shipments from plants that fail to meet the highest standards because buyers consider meat quality, production costs, and other factors in their purchasing decisions. Plants that periodically failed to meet the Cat 1 standard typically attained Cat 1 at a later date and may have consistently done so. Plants repeatedly not meeting the Cat 1 standard may have sold to less-discriminating buyers and may have felt little pressure to improve their performance when their identities were disclosed. Their least-cost option may have been to endure the greater regulatory scrutiny imposed on poorly-performing plants rather than to invest in food-safety practices. These incentives suggest that a policy of public disclosure of Salmonella results is unlikely to yield universal attainment of the strictest standards. The result, however, may be economically efficient because the buyers served by non-attaining plants may not require the level of food safety mandated by a regulator.

The article makes several contributions to the literature on food safety and information disclosure in credence attributes. Starbird (2005) showed that third-party testing can overcome the moral hazard inherent in production under asymmetric information, as in food safety. In the case of chicken carcasses, however, the standard itself was lax, enabling moral hazard to flourish despite testing. Moreover, the mechanism used to set the standard also suffered from moral hazard because standards were based on past performance. This paper presents evidence that public disclosure of poor performance on Salmonella tests helped overcome moral hazard at both levels and contributed to better performance on Salmonella tests. Other contributions include the following. First, this is among the first papers to examine public disclosure of food-safety information in a market comprised of commercial buyers and sellers. Second, the paper shows evidence that the credible threat of quality disclosure (subsequently implemented) encouraged better performance on Salmonella tests before the policy was actually imposed, and may have motivated plants to perform at levels surpassing the FSIS highest standard. Third, the paper highlights different performance pressure points across the chicken industry: plants with poor food-safety records responded more to FSIS actions dealing with stricter regulatory stringency while plants with better food-safety records reacted more strongly to changes in public disclosure policies. These results may explain why plant Salmonella test results do not cluster at or just below the FSIS standards. Plants respond to diverse incentives, leading some plants to barely meet the standard and others to easily surpass it. Finally, the paper shows that quality disclosure is not a panacea: some plants continued to have high levels of Salmonella even after public disclosure was fully implemented.

\section{Acknowledgments}

The authors received helpful comments from the editor Tim Richards, three anonymous 
reviewers, seminar participants at the University of California at Davis and the University of Connecticut, and colleagues at the USDA Economic Research Service. James Wilkus of the USDA Food Safety and Inspection Service provided the data that was analyzed. The findings and conclusions in this publication are those of the author(s) and should not be construed to represent any official USDA or U.S. government determination or policy. The research was supported by the USDA, Economic Research Service.

\section{Supplementary Material}

Supplementary material are available at American Journal of Agricultural Economics online.

\section{References}

Akerlof, G.A. 1970. The Market for 'Lemons': Quality Uncertainty and the Market Mechanism. Quarterly Journal of Economics 84 (3): 488-500.

Allison, P. 2009. Fixed Effects Regression Models. Thousand Oaks, CA: Sage Publications.

Allison, P., and N.A. Christakis. 2006. FixedEffects Methods for the Analysis of Nonrepeated Events. Sociological Methodology 36 (1): 155-72

Becker, A.L. 2004. USDA Finding Salmonella Less Often in Meat. CIDRAP News. August 10, 2004. Center for Infectious Disease Research and Policy: University of Minnesota. http://www.cidrap.umn. edu/news-perspective/2004/08/usda-findingsalmonella-less-often-meat (accessed July 26, 2018).

Bennear, L.S., and S.M. Olmstead. 2008. The impacts of the "right to know": Information disclosure and the violation of drinking water standards, Journal of Environmental Economics and Management, 56 (2, September): 117-130.

Bovay, J., and A.S. Daniel. 2018. Economic Effects of the U.S. Food Safety Modernization Act. Applied Economic Perspectives and Policy 40 (3): 402-420.

Cameron, A.C., and P.K. Trivedi. 2005. Microeconometrics: Methods and Applications. New York: Cambridge University Press.
Chamberlain, G.A. 1980. Analysis of Covariance with Qualitative Data. Review of Economic Studies 47 (1): 225-38.

Dulleck, U., R. Kerschbamer, and M. Sutter. 2011. The Economics of Credence Goods: An Experiment on the Role of Liability, Verifiability, Reputation, and Competition. American Economic Review 101 (April): 530-59.

Golan, E., T. Roberts, E. Salay, J. Caswell, M. Ollinger, and D. Moore. 2004. Food Safety Innovation in the United States: Evidence from the Meat Industry. Washington DC: U.S. Department of Agriculture, Economic Research Service, Agricultural Economic Report 831.

Greene, W. 2003. Econometric Analysis. New York: Prentice Hall.

Grossman, S.J., and O.D. Hart. 1983. An Analysis of the Principal-Agent Problem. Econometrica 51 (1): 7-45.

Holmström, B. 1979. Moral Hazard and Observability. Bell Journal of Economics 10 (1): 74-91. 1982. Moral Hazard in Teams. Bell Journal of Economics 13 (2): 324-40.

Honoré, B.E. 1992. Trimmed LAD and Least Squares Estimation of Truncated and Censored Regression Models with Fixed Effects. Econometrica 60: 533-65.

Interagency Food Safety Analytics Collaboration. 2018. Foodborne Illness Source Attribution Estimates for 2016 for Salmonella, Escherichia coli O157, Listeria monocytogenes, and Campylobacter Using MultiYear Outbreak Surveillance Data, United States. Atlanta, GA and Washington DC: U.S. Department of Health and Human Services, CDC, FDA, USDA-FSIS.

Jin, G.Z., and P. Leslie. 2003. The Effect of Information on Product Quality: Evidence from Restaurant Hygiene Grade Cards. Quarterly Journal of Economics 118 (2): 409-51.

Lusk, J.L., and T.C. Schroeder. 2002. Effects of Meat Recalls on Futures Market Prices. Agricultural and Resource Economics Review 31 (1): 47-58.

Muth, M., M. Fahimi, S.A. Karns, and Y. Li. 2007. Analysis of Food Safety Performance in Meat and Poultry Establishments. Revised Final Report Contract No. 53-3A94- 3-12, Task Order 18. Prepared for Flora Tsui and Jim Wilkus of Food Safety and Inspection Service by RTI International: Triangle Park, North Carolina. 
Norton, E.C., H. Wang, and C. Ai. 2004. Computing Interaction Effects and Standard Errors in Logit and Probit Models. Stata Journal: Promoting Communications on Statistics and Stata 4 (2): 154-67.

Ollinger, M., and J. Bovay. 2018. Pass or Fail: Economic Incentives to Reduce Salmonella Contamination in Ground Beef Sold to the National School Lunch Program. American Journal of Agricultural Economics 100 (2): 414-33.

Ollinger, M., and D. Moore. 2008. The Economic Forces Driving Food Safety Quality in Meat and Poultry. Review of Agricultural Economics 30 (2): 289-310.

. 2009. The Direct and Indirect Costs of Food Safety Regulation. Review of Agricultural Economics 31 (2): 247-65.

Ollinger, M., D. Moore, and R. Chandran. 2004. Meat and Poultry Plants' Food Safety Investments: Survey Findings. Washington DC: U.S. Department of Agriculture, Economic Research Service, Technical Bulletin 1911.

Ollinger, M., and V. Mueller. 2003. Managing for Safer Food: The Economics of Sanitation and Process Controls in Meat and Poultry Establishments. Washington DC: U.S. Department of Agriculture, Economic Research Service, Agricultural Economic Report 817.

Ollinger, M., J. Wilkus, M. Hrdlicka, and J. Bovay. 2017. Public Disclosure of Tests for Salmonella: the Effects on Food Safety Performance in Chicken Establishments. Washington DC: U.S. Department of Agriculture, Economic Research Service, Economic Research Report No. 231.

Painter, J.A., R.M. Hoekstra, T. Ayers, R.V. Tauxe, C.R. Braden, F.J. Angulo, and P. M. Griffin. 2013. Attribution of Foodborne Illnesses, Hospitalizations, and Deaths to Food Commodities by Using Outbreak Data, United States, 1998-2008. Emerging Infectious Diseases (19) (3).
Piggott, N.E., and T.L. Marsh. 2004. Does Food Safety Information Impact U.S. Meat Demand? American Journal of Agricultural Economics 86 (1): 154-74.

Pozo, V.F., and T. Schroeder. 2016. Evaluating the Costs of Meat and Poultry Recalls to Food Firms Using Stock Returns. Food Policy 59: 66-77.

Roe, B., and I. Sheldon. 2007. Credence Good Labeling: The Efficiency and Distributional Implications of Several Policy Approaches. American Journal of Agricultural Economics 89 (4): 1020-33.

Starbird, S.A. 2005. Moral Hazard, Inspection Policy, and Food Safety. American Journal of Agricultural Economics 87 (1): $15-27$.

Stock, J.H., and M.W. Watson. 2011. Introduction to Econometrics, 3rd Ed. Boston: Pearson.

Thomsen, M.R., R. Shiptsova, and S.J. Hamm. 2006. Sales Responses to Recalls for Listeria monocytogenes: Evidence from Branded Ready-to-Eat Meats. Review of Agricultural Economics 28 (4): 482-93.

U.S. Depatment of Agriculture, Food Safety and Inspection Service. 2006. Salmonella Verification Sample Result Reporting: Agency Policy and Use in Public Health Protection; Notice and Response to Comments. Federal Register 71 (38): 9772-77.

. 2012. Changing the Set Sizes in Raw Ground Poultry Sampling. Washington DC: U.S. Department of Agriculture, Food Safety Inspection Service. August. https://www.fsis.usda.gov/wps/wcm/connect/ fd2683bb-c409-4986-9d8a-49bb88ff6d80/ Set_Sizes_in_Ground_Poultry_Sampling. pdf?MOD=AJPERES.

Williams, M.S., and E.D. Ebel. 2012. Estimating Changes in Public Health following Implementation of Hazard Analysis and Critical Control Point in the United States Broiler Slaughter Industry. Foodborne Pathogen Diseases 9 (1): 59-67. 